\title{
Psychosocial Determinants of Attrition in a Longitudinal Study of Tobacco Use in Youth
}

\author{
Ann Post, ${ }^{1}$ Hans Gilljam, ${ }^{1}$ Sven Bremberg, ${ }^{1}$ and Maria Rosaria Galanti ${ }^{2}$ \\ ${ }^{1}$ Division of Social Medicine, Department of Public Health Sciences, Karolinska Institute, P.O. Box 170 70, 10462 Stockholm, Sweden \\ ${ }^{2}$ Division of Public Health Epidemiology, Department of Public Health Sciences, Karolinska Institute, Norrbacka plan 2, \\ 17176 Stockholm, Sweden
}

Correspondence should be addressed to Ann Post, ann.post@ki.se

Received 11 October 2011; Accepted 2 January 2012

Academic Editors: K. F. Harrington and D. T. L. Shek

Copyright () 2012 Ann Post et al. This is an open access article distributed under the Creative Commons Attribution License, which permits unrestricted use, distribution, and reproduction in any medium, provided the original work is properly cited.

To gain knowledge on psychosocial characteristics that predict the propensity of participation in longitudinal studies, attrition was analysed in a cohort of 3020 adolescents participating in the baseline survey of a longitudinal study with repeated followup focusing on adolescents' tobacco use. During the followup surveys, the proportion of responders was constantly at or above $90 \%$. There were 941 adolescents $(31.2 \%)$ who failed to participate in at least one of the six followup surveys. Boys had a fifty percent increased risk of nonparticipation compared with girls. Adolescents in families with experience of divorce, unemployment, and change of residence had a higher risk of nonparticipation. An increasing number of stressful life events during the previous year, uptake of tobacco use, number of friends, perceived performance at school, truancy, and alcohol use during the last term also independently associated with nonparticipation. Diverse psychosocial characteristics are independently associated with nonparticipation of youths in longitudinal studies.

\section{Introduction}

The recruitment of adolescents into longitudinal studies can be challenging, especially if repeated contacts are required. In such studies, failure of contact at any point in time entails loss of information with possible problems of validity of the results $[1,2]$. Several methods for limiting or reducing the impact of attrition have been proposed: collection of data at school and tracking absentees by postal questionnaires, telephone, or home interviews $[3,4]$. Payment and rewards have also been used [5]. On the other hand, the medium of data collection does not seem to have a decisive impact on response rates, as shown by studies comparing web forms versus paper-forms to collect information on alcohol and tobacco among students $[6,7]$. It has been repeatedly shown, however, that youths who are prone to drop out are more likely to come from a single-parent household, to be less successful in school, and to be more often substance users $[5,8]$.

As far as gender is concerned, some studies have found that females are more prone to participate than males $[9,10]$.
Whether psychosocial characteristics affect the propensity of the adolescents to participate in longitudinal studies independently from behavioral factors is not known. In order to gain knowledge on this matter, we analyzed the information from the BROMS study (Children's Smoking and Environment in the Stockholm County), a longitudinal study of adolescents' tobacco use in the Stockholm region of Sweden.

\section{Materials and Methods}

2.1. Study Population. The study sample consisted of 3020 5th grade students (1537 boys and 1483 girls), of mean age 11.6 yrs residing in the county of Stockholm in 1998. The study was initiated to assess determinants of uptake of cigarettes and snus (the traditional Swedish type of moist oral snuff). A two-step sampling was used. First, a random sample of schools in the region was selected. The guardians of the children in the consenting schools were asked to provide written permission to their children's enrolment in the cohort. Details on the study population and participation 
TABLE 1: Responders, nonresponders, and dropouts at each followup survey, The BROMS Cohort Study, 1998-2005.

\begin{tabular}{|c|c|c|c|c|c|c|}
\hline & \multicolumn{6}{|c|}{ Followup survey } \\
\hline & 1 & 2 & 3 & 4 & 5 & 6 \\
\hline Available cohort* members & 3020 & 3011 & 2976 & 2952 & 2910 & 2852 \\
\hline Responders & 2904 & 2882 & 2809 & 2689 & 2621 & 2489 \\
\hline$(\%)$ & $(96.2)$ & $(95.7)$ & $(94.4)$ & $(91.1)$ & $(90.1)$ & $(87.3)$ \\
\hline Non responders & 107 & 94 & 143 & 221 & 231 & 350 \\
\hline$(\%)$ & $(3.5)$ & $(3.1)$ & $(4.8)$ & $(7.5)$ & $(7.9)$ & $(12.2)$ \\
\hline Drop-outs & 9 & 35 & 24 & 42 & 58 & 13 \\
\hline$(\%)$ & $(0.3)$ & $(1.2)$ & $(0.8)$ & $(1.4)$ & $(2.0)$ & $(0.5)$ \\
\hline
\end{tabular}

${ }^{*}$ Available cohort members are students who had not left permanently the cohort at the time of the survey.

rates at recruitment both at the school and at the family level have been published previously [11].

2.2. Data Collection. Information from the children was collected every year (except for the first year after compulsory school), thus yielding one baseline and six followup surveys. The survey instrument was a self-completed questionnaire covering questions on health behaviors, psychosocial characteristics and experience of substance use, particularly tobacco and alcohol. At baseline and during the first four followup waves the questionnaires were completed in the classroom, sealed into an anonymous envelope and collected by the teacher. At the two remaining followup waves the questionnaires were sent to the participants' homes and returned by prepaid mail. Up to five attempts were made to reach nonresponders, twice by ordinary mail and three times by telephone, when the adolescents were given the opportunity to answer the questionnaire by phone interview. At each school survey, all participants received low-cost gifts, such as pens, while on the two surveys after compulsory school, early responders (within two weeks) were rewarded with a cinema ticket. The bulk of data collection was completed within two months during each survey. In the course of the study, tracking of participants in case of change of school or address was accomplished through the school rosters and/or the tax authority registers, using the unique national personal number as identifier.

\subsection{Measures}

2.3.1. Sociodemographics. Demographic information collected at baseline included gender, age, country of birth, and parental cohabitation. Parental education was based on the highest number of school years attended by either parent at the time of the baseline survey. This was categorized as compulsory education ( $\leq 9 \mathrm{yrs})$, senior high school education (10-12 yrs), and college level education ( $>12 \mathrm{yrs}$ ).

2.3.2. Psychosocial Measures. Some selected psychosocial characteristics were collected at baseline and in grade 6, 7, and 8. Stressful events during the past year included change of residence, change of school, parental divorce, parental unemployment, and death of kindred. Besides considering each event per se, a categorical variable was created cumulating the total number of reported events $(0$, 1,2 , and above). The number of friends met regularly every week in leisure time was categorized in 0 (none), 1-4, and 5 or more. The question whether the adolescents found it easy to confide in their mother, father, or other adults was recoded into a dichotomous variable as "Confidence in any adult" (for answers: Very easy/Easy) and "No confidence in any adult" (for the answers: Difficult/Very difficult/Adult not available in every option). School truancy during the last term was categorized as $0,1-3, \geq 4$ days. The judgment of own school proficiency compared to classmates was measured by the alternatives "Very good", "Good", "Average", and "Below average".

2.3.3. Tobacco Use and Alcohol Consumption. Tobacco use ever in life at the baseline survey and followup was categorized as positive answer to the question "Did you ever try smoking a cigarette, even a single puff?" and "Did you ever try snus?" Alcohol drinking was first investigated at the 7 th grade survey (13 years of age) through the following questions" Did you drink any beer, wine or spirits during last school term?" with response alternatives: Never used; No; Yes, once; Yes, more than once. Intoxication drinking was assessed by the question "Have you ever consumed so much alcohol that you got drunk?” (Yes/No).

2.4. Outcome. At any followup survey, available (contactable) cohort members were those adolescents who took part in the baseline study, were still alive, and did not explicitly refuse continued participation prior to the date of data collection. On the basis of the response history at the end of the data collection period, we defined the available members as "Responders" if they had a completed or partially completed questionnaire responded by mail or by phone. Adolescents who had not filled in or returned the questionnaire or completed a phone interview were identified as "Non responders." Finally, we labeled as "Dropouts" subjects who either communicated to the study team that they were not willing to further participate in the study or died during followup.

For the purpose of this study, a dichotomous outcome was considered, where nonparticipation was defined as failure to respond to any survey after baseline. 
TABLE 2: Behavioural and psychosocial characteristics at baseline as predictors of non-participation in any followup survey.

\begin{tabular}{|c|c|c|c|c|}
\hline & $n$ & Non responder or dropout $\%$ & $x^{2}$ & $P$ \\
\hline \multicolumn{5}{|l|}{ Gender } \\
\hline Boys & 1537 & 36.1 & \multirow{2}{*}{35.76} & \multirow{2}{*}{$<0.000$} \\
\hline Girls & 1483 & 26.0 & & \\
\hline \multicolumn{5}{|c|}{ Born in Sweden } \\
\hline Yes & 2817 & 30.4 & \multirow{2}{*}{10.51} & \multirow{2}{*}{0.001} \\
\hline No & 195 & 41.5 & & \\
\hline \multicolumn{5}{|c|}{ Mother and father living together } \\
\hline Yes & 2196 & 28.2 & \multirow{2}{*}{33.34} & \multirow{2}{*}{$<0.000$} \\
\hline No & 805 & 39.3 & & \\
\hline \multicolumn{5}{|c|}{ Change of residence } \\
\hline No & 2479 & 29.5 & \multirow[t]{2}{*}{19.48} & \multirow{2}{*}{$<0.000$} \\
\hline Yes & 408 & 40.4 & & \\
\hline \multicolumn{5}{|c|}{ Change of school } \\
\hline No & 2681 & 30.2 & \multirow{2}{*}{9.92} & \multirow{2}{*}{0.002} \\
\hline Yes & 184 & 41.3 & & \\
\hline \multicolumn{5}{|c|}{ Parental divorce } \\
\hline No & 2684 & 30.1 & \multirow{2}{*}{17.46} & \multirow{2}{*}{$<0.000$} \\
\hline Yes & 175 & 45.1 & & \\
\hline \multicolumn{5}{|c|}{ Death of kindred } \\
\hline No & 2117 & 30.4 & \multirow{2}{*}{0.74} & \multirow{2}{*}{0.390} \\
\hline Yes & 776 & 32.1 & & \\
\hline \multicolumn{5}{|c|}{ Parental unemployment } \\
\hline No & 2607 & 30.0 & \multirow{2}{*}{9.88} & \multirow{2}{*}{0.002} \\
\hline Yes & 244 & 39.8 & & \\
\hline \multicolumn{5}{|c|}{ Number of stressful events last year* } \\
\hline 0 & 1698 & 28.3 & \multirow{3}{*}{19.91} & \\
\hline 1 & 878 & 33.5 & & $<0.000$ \\
\hline$>1$ & 390 & 39.0 & & \\
\hline Number & & & & \\
\hline 0 & 20 & 55.0 & & \\
\hline $1-4$ & 1818 & 28.4 & 18.97 & $<0.000$ \\
\hline$>4$ & 1150 & 34.9 & & \\
\hline Ever sm & & & & \\
\hline No & 2455 & 28.9 & 2998 & $<0.000$ \\
\hline Yes & 556 & 40.8 & 29.90 & \\
\hline Ever snu & & & & \\
\hline No & 2846 & 30.8 & 1.50 & 0.221 \\
\hline Yes & 167 & 35.3 & 1.50 & 0.221 \\
\hline Ever tob & & & & \\
\hline No & 2397 & 28.7 & 31.23 & $<0.000$ \\
\hline Yes & 609 & 40.4 & 31.23 & $<0.000$ \\
\hline
\end{tabular}

2.5. Statistical Analysis. Data analyses were conducted using SPSS 10.0.5 for Windows (SPSS Inc., Chicago, IL). In univariate analyses, the proportion of nonresponders in categories of the predictors was compared with the expected proportions by means of the chi-square statistic. The level for the statistical significance was conventionally set at 95\%
$(P<0.05)$. Predictors that were found significantly associated to non-participation in the univariate analysis were then analysed in multivariable regression models using ordinary logistic regression. Odds ratios (ORs) of nonparticipation and their corresponding 95\% confidence intervals (CI) were used as measure of association and precision, respectively. 
TABLE 3: Behavioural and psychosocial characteristics at followup as predictors of subsequent non-participation.

\begin{tabular}{|c|c|c|c|c|c|}
\hline & Grade when measured & $n$ & $\begin{array}{c}\text { Non responderor dropout } \\
(\%)\end{array}$ & $\chi^{2}$ & $P$ \\
\hline Any adult to confide in & 6 & & & \multirow{3}{*}{0.29} & \multirow{3}{*}{0.591} \\
\hline Yes & & 2777 & 28.4 & & \\
\hline No & & 89 & 25.8 & & \\
\hline Ever smoker & 7 & & & \multirow{3}{*}{67.65} & \multirow{3}{*}{$<0.000$} \\
\hline No & & 1530 & 19.6 & & \\
\hline Yes & & 1342 & 33.1 & & \\
\hline Ever snus user & 7 & & & \multirow{3}{*}{72.63} & \multirow{3}{*}{$<0.000$} \\
\hline No & & 2289 & 22.4 & & \\
\hline Yes & & 587 & 39.7 & & \\
\hline Any alcohol use during latest term & 7 & & & \multirow{3}{*}{19.27} & \multirow{3}{*}{$<0.000$} \\
\hline No & & 1756 & 22.9 & & \\
\hline Yes & & 1100 & 30.3 & & \\
\hline Intoxication drinking latest term & 7 & & & \multirow{3}{*}{7.32} & \multirow{3}{*}{0.007} \\
\hline No & & 962 & 27.7 & & \\
\hline Yes & & 477 & 34.6 & & \\
\hline Ever smoker & 8 & & & \multirow{3}{*}{46.97} & \multirow{3}{*}{$<0.000$} \\
\hline No & & 1197 & 16.0 & & \\
\hline Yes & & 1608 & 26.9 & & \\
\hline Ever snus user & 8 & & & \multirow{3}{*}{72.91} & \multirow{3}{*}{$<0.000$} \\
\hline No & & 1943 & 17.8 & & \\
\hline Yes & & 861 & 32.3 & & \\
\hline Truancy latest term (days) & 8 & & & \multirow{4}{*}{50.00} & \multirow{4}{*}{$<0.000$} \\
\hline 0 & & 1980 & 19.0 & & \\
\hline $1-3$ & & 483 & 26.3 & & \\
\hline$\geq 4$ & & 313 & 35.8 & & \\
\hline $\begin{array}{l}\text { Own beliefs of teachers judgement of school } \\
\text { proficiency compared to classmates }\end{array}$ & 8 & & & \multirow{5}{*}{30.48} & \multirow{5}{*}{$<0.000$} \\
\hline Very good & & 436 & 20.9 & & \\
\hline Good & & 1219 & 18.5 & & \\
\hline Average & & 984 & 25.4 & & \\
\hline Below average & & 113 & 37.2 & & \\
\hline $\begin{array}{l}\text { Own judgement of school proficiency compared to } \\
\text { classmates }\end{array}$ & 8 & & & \multirow{5}{*}{28.92} & \multirow{5}{*}{$<0.000$} \\
\hline Very good & & 559 & 24.2 & & \\
\hline Good & & 1270 & 17.5 & & \\
\hline Average & & 820 & 27.0 & & \\
\hline Below average & & 100 & 25.0 & & \\
\hline
\end{tabular}

\section{Results}

Among the 3020 youths participating in the baseline survey and constituting the study sample, 2397 (79.4\%) had never tried cigarettes or snus at baseline. Ever smoking was reported by 556 (18.5\%) and ever snus use by 167 (5.5\%) of the subjects. Current tobacco use (at least monthly) was reported by 12 subjects $(0.4 \%)$. The proportion of children with at least one parent with college education was higher than the average of the regional population 49.6 percent against an average of 39.5 percent of comparable age group for the whole Stockholm County.

During the followup surveys 1 through 5 , the proportion of responders was constantly at or above 90\% (range 90.1$96.2 \%)$ and slightly declined only at the end of followup (Table 1).

During the study period, 181 subjects $(6.0 \%)$ of those initially recruited dropped out of the study permanently, that is, either refused continued participation or died (Table 1). The dropout rates fluctuated between $0.3 \%$ and $2.0 \%$, of 
TABLE 4: Odds ratios of nonparticipation according to behavioural psychosocial characteristics at baseline.

\begin{tabular}{lrr}
\hline Predictor & \multicolumn{1}{c}{$\begin{array}{c}\mathrm{OR}^{(1)} \\
(95 \% \mathrm{CR})\end{array}$} \\
\hline Gender (boys versus girls) & $1.6(1.4-1.9)$ & $1.5(1.3-1.8)$ \\
Ever smoker at baseline (versus never) & $1.7(1.4-2.1)$ & $1.4(1.2-1.7)$ \\
Not born in Sweden (versus born in Sweden) & $1.6(1.2-2.2)$ & $1.6(1.2-2.2)$ \\
Mother and father living together at baseline (no versus yes) & $1.6(1.4-1.9)$ & $1.5(1.2-1.8)$ \\
Change of residence (yes versus no) & $1.6(1.3-2.0)$ & $1.3(1.0-1.7)$ \\
Parental unemployment (yes versus no) & $1.5(1.2-2.0)$ & $1.4(1.0-1.8)$ \\
Number of friends in leisure time (reference: 1-4) & $3.1(1.3-7.5)$ & $2.4(0.9-6.6)$ \\
$\quad$ None & $1.3(1.2-1.6)$ & $1.3(1.1-1.5)$ \\
$\quad>4$ &
\end{tabular}

${ }^{(1)}$ Unadjusted.

${ }^{(2)}$ Adjusted for all other predictors in table.

the eligible, without clear trends over time. All in all, 941 adolescents (31.2\%) failed to participate in one or more of the followup surveys.

In univariate analyses, most psychosocial characteristics measured at baseline were significantly associated with nonresponse any time during the study (Table 2).

Being born outside Sweden, not living together with both legal parents, several stressful life events during the year preceding the baseline survey corresponded to a higher proportion of nonparticipating subjects. Subjects reporting no friends or more than 4 friends with whom they spent their leisure time had lower participation than those reporting a group of 1-4 friends. Ever smokers at baseline, but not ever snus users, had lower participating rates than never users of tobacco. Analyses of the same predictors measured during followup resulted in very similar findings.

Some indicators of problem behaviors or psychosocial distress during followup also predicted nonparticipation in subsequent surveys. This was the case for recent alcohol drinking and intoxication drinking, smoking and snus use, school truancy, and perceived poor academic performance (Table 3).

On the other hand, access to supporting adults did not predict participation. The results described above were substantially unchanged when the analysis was restricted to the two final waves among responders in grade nine, the last grade of compulsory school. Most associations remained statistically significant in multivariate regression models including all predictors that were associated to nonparticipation in univariate analysis. Significant predictors of non-participation measured at baseline were male gender, being born outside Sweden, family circumstances and having initiated smoking (Table 4).

On the other hand, own perception of school performance and alcohol use during last term, including intoxication drinking, no longer predicted participation after adjustment for other factors (Table 5).

\section{Discussion}

In this cohort study with low attrition, only 181 adolescents (6\%) dropped out permanently during the six years followup period, while occasional nonparticipation slowly rose in the course of time from $3 \%$ to $12 \%$. Consistent with previous research, females were more prone to participate than males $[9,10]$. We found that many psychosocial traits and behavioural factors beside tobacco use were significant predictors of adolescents' participation. Although the choice of these predictors was somewhat arbitrary, all of them indicated either an unstable family environment or behavioural problems, such as school truancy, low school performance or substance use. An increasing number of stressful events, most of them connected with family disruption, change of residence, and/or of school, occurring in the previous year, was associated to nonresponse in a dose-response fashion. Noteworthy, the correlation of the predictors under study with nonparticipation was evident both at baseline and throughout the study period, thus indicating that the association was not dependent on the subjects' age. An interesting observation was that both the absence of close friends with whom to spend the leisure time and a high number of friends (more than 4) predicted non response, compared to having a group of 1-4 friends. These findings provide support to poorer treatment retention and followup detected in studies analysing internalizing-externalizing behaviour in youth $[12,13]$.

In multivariate analyses, we found that psychosocial distress and the uptake of tobacco use were independent predictors of nonparticipation at followup. Previous research on determinants of nonparticipation has focussed on selective loss of tobacco users, to conclude that the external validity of most surveys may be compromised by this selection [14]. However, there are longitudinal studies showing no relation between demographic or psychosocial variables, including smoking experience, and retention of the participants [15].

Our results show that tobacco use is neither the only nor the strongest predictor of nonparticipation. Furthermore, 
TABLE 5: Odds ratios of nonparticipation according to behavioural and psychosocial characteristics at different times during followup.

\begin{tabular}{|c|c|c|}
\hline Predictors/Grade & $\begin{array}{c}\mathrm{OR}^{(1)} \\
(95 \% \mathrm{CI})\end{array}$ & $\begin{array}{c}\mathrm{OR}^{(2)} \\
(95 \% \mathrm{CI})\end{array}$ \\
\hline \multicolumn{3}{|l|}{ Grade 7} \\
\hline Gender (boys versus girls) & $1.8(1.6-2.2)$ & $1.8(1.4-2.3)$ \\
\hline Ever smoker (versus never) & $2.0(1.7-2.4)$ & $1.6(1.2-2.1)$ \\
\hline Ever snus user (versus never) & $2.3(1.9-2.8)$ & $1.5(1.2-1.9)$ \\
\hline Any alcohol use during last term (yes versus no) & $1.5(1.2-1.7)$ & $0.9(0.7-1.2)$ \\
\hline Intoxication drinking last term (yes versus no) & $1.4(1.1-1.8)$ & $1.2(0.9-1.5)$ \\
\hline \multicolumn{3}{|l|}{ Grade 8} \\
\hline Gender (boys versus girls) & $1.9(1.5-2.2)$ & $1.9(1.5-2.3)$ \\
\hline Ever smoker (versus never) & $1.9(1.6-2.3)$ & $1.5(1.2-1.9)$ \\
\hline Ever snus user (versus never) & $2.2(1.8-2.7)$ & $1.3(1.1-1.7)$ \\
\hline \multicolumn{3}{|l|}{ Truancy latest term (reference: no truancy) } \\
\hline $1-3$ days & $1.5(1.2-1.9)$ & $1.3(1.0-1.7)$ \\
\hline$\geq 4$ days & $2.4(1.8-3.1)$ & $1.9(1.4-2.5)$ \\
\hline \multicolumn{3}{|c|}{ Own beliefs of teacher's judgement of school proficiency compared to classmates (reference: very good) } \\
\hline Good & $0.9(0.7-1.1)$ & $1.0(0.7-1.4)$ \\
\hline Average & $1.3(1.0-1.7)$ & $1.1(0.7-1.6)$ \\
\hline Below average & $2.2(1.4-3.5)$ & $1.5(0.8-2.7)$ \\
\hline \multicolumn{3}{|l|}{ Beliefs of own school proficiency (reference: very good) } \\
\hline Good & $1.0(0.6-1.6)$ & $0.7(0.5-1.0)$ \\
\hline Average & $0.6(0.4-1.0)$ & $1.1(0.8-1.5)$ \\
\hline Below average & $1.1(0.7-1.8)$ & $0.7(0.4-1.3)$ \\
\hline
\end{tabular}

characteristics indicating social vulnerability were linked to adolescents' nonparticipation despite the initial selection, because children were recruited mostly from families with high social status [11].

4.1. Study Limitations and Strengths. Although the present study did not seek to specify all psychosocial factors associated with attrition of adolescents in longitudinal studies, it may serve as a starting point identifying variables predicting retention. Strength of the findings is the repeated measurements of the psychosocial determinants during the study period.

Our findings are in general agreement with previous observations that factors facilitating or hindering adolescent participation in studies fall into four classes: demographics, individual variables, family characteristics, and logistical factors, such as frequent changes of residence [5]. Several studies have investigated and recommended tracking and followup methods to minimize attrition $[2,3,11,16]$. Studies of children and adolescents must develop and implement methods to increase participation of vulnerable subgroups, such as those living in conditions of psychosocial distress. Additional variables may be warranted to identify these groups and possibly increase participation rates.

In conclusion, we suggest that baseline psychosocial characteristics of a recruited sample can be used to identify cues for an efficient followup, that is, to avoid loss of individuals of particular interest for the accuracy and validity of the observations to be conducted.

\section{Acknowledgments}

The Ethical Board of Karolinska University Hospital approved the study. Financial support was provided by Stockholm County Council and by The Swedish Research Council, grant no. 345-2002-35. All authors declare that there is no conflict of interest. The article is original, has not been formally published in any other peer-reviewed journal, is not under consideration by any other journal, and does not infringe any existing copyright.

\section{References}

[1] C. A. Mills, L. L. Pederson, J. J. Koval, S. M. Gushue, and J. A. L. Aubut, "Longitudinal tracking and retention in a school-based study on adolescent smoking: costs, variables, and smoking status," Journal of School Health, vol. 70, no. 3, pp. 107-112, 2000.

[2] T. C. Morrison, D. R. Wahlgren, M. F. Hovell et al., "Tracking and follow-up of 16,915 adolescents: minimizing attrition bias," Controlled Clinical Trials, vol. 18, no. 5, pp. 383-396, 1997.

[3] A. Boys, J. Marsden, G. Stillwell, K. Hatchings, P. Griffiths, and M. Farrell, "Minimizing respondent attrition in longitudinal 
research: practical implications from a cohort study of adolescent drinking," Journal of Adolescence, vol. 26, no. 3, pp. 363373, 2003.

[4] J. A. Epstein and G. J. Botvin, "Methods to decrease attrition in longitudinal studies with adolescents," Psychological Reports, vol. 87, no. 1, pp. 139-140, 2000.

[5] D. Zand, N. R. Thomson, M. Dugan, J. A. Braun, P. Holterman-Hommes, and P. L. Hunter, "Predictors of retention in an alcohol, tobacco, and other drug prevention study," Evaluation Review, vol. 30, no. 2, pp. 209-222, 2006.

[6] S. E. McCabe, C. J. Boyd, A. Young, S. Crawford, and D. Pope, "Mode effects for collecting alcohol and tobacco data among 3rd and 4th grade students: a randomized pilot study of Webform versus paper-form surveys," Addictive Behaviors, vol. 30, no. 4, pp. 663-671, 2005.

[7] P. M. Webb, G. D. Zimet, J. D. Fortenberry, and M. J. Blythe, "Comparability of a computer-assisted versus written method for collecting health behavior information from adolescent patients," Journal of Adolescent Health, vol. 24, no. 6, pp. 383 388, 1999.

[8] S. A. Weisman and D. C. Gottfredson, "Attrition from after school programs: characteristics of students who drop out," Prevention Science, vol. 2, no. 3, pp. 201-205, 2001.

[9] K. E. Bauman, S. T. Ennett, V. A. Foshee, M. Pemberton, and K. Hicks, "Correlates of participation in a family-directed tobacco and alcohol prevention program for adolescents," Health Education and Behavior, vol. 28, no. 4, pp. 440-461, 2001.

[10] B. C. Martinson, D. Lazovich, H. A. Lando, C. L. Perry, P. G. McGovern, and R. G. Boyle, "Effectiveness of monetary incentives for recruiting adolescents to an intervention trial to reduce smoking," Preventive Medicine, vol. 31, no. 6, pp. 706713, 2000.

[11] A. Post, M. R. Galanti, and H. Gilljam, "School and family participation in a longitudinal study of tobacco use: some methodological notes," European Journal of Public Health, vol. 13, no. 1, pp. 75-76, 2003.

[12] A. King, B. Wold, C. Tudor-Smith, and Y. Harel, "The health of youth. A cross-national survey," WHO Regional Publications. European series, vol. 69, pp. 1-222, 1996.

[13] K. C. Winters, R. D. Stinchfield, W. W. Latimer, and A. Stone, "Internalizing and externalizing behaviors and their association with the treatment of adolescents with substance use disorder," Journal of Substance Abuse Treatment, vol. 35, no. 3, pp. 269-278, 2008.

[14] E. T. Moolchan and R. Mermelstein, "Research on tobacco use among teenagers: ethical challenges," Journal of Adolescent Health, vol. 30, no. 6, pp. 409-417, 2002.

[15] K. R. Diviak, S. K. Wahl, J. J. O’Keefe, R. J. Mermelstein, and B. R. Flay, "Recruitment and retention of adolescents in a smoking trajectory study: who participates and lessons learned," Substance Use and Misuse, vol. 41, no. 2, pp. 175-182, 2006.

[16] O. Siddiqui, B. R. Flay, and F. B. Hu, "Factors affecting attrition in a longitudinal smoking prevention study," Preventive Medicine, vol. 25, no. 5, pp. 554-560, 1996. 